\title{
An Investigating Study on the Cultural City Branding Strategy
}

\section{문화도시 활성화를 위한 도시브랜드전략의 탐색적 연구 -1차 법정문화도시를 중심으로-}

\author{
Won Bae $\mathrm{Ji}^{1}$, Hyun Joong $\mathrm{Yu}^{2}$, Hae Won Chung ${ }^{3}$ \\ 지원배 ${ }^{1}$, 유현중 2 , 정해원 ${ }^{3}$ \\ ${ }^{1}$ Professor, Division of Advertising, PR, \& Visual Communication, Hanshin University, Korea, \\ $7321 @$ daum.net \\ ${ }^{2}$ Professor,Politics\&Communication Department, Hannam University, Korea,yhj1075@paran.com \\ ${ }^{3}$ Professor, Advertising\& PR Department, Kosin University, Korea, lamerun@naver.com
}

Corresponding author: Hae Won Chung

\begin{abstract}
City branding is a strategy aiming city regeneration and securing city competitiveness. Recently, the government selected seven cities as the first cities for strategic city branding. They are Bucheon in Gyeonggi Province, Wonju in Gangwon Province, Cheongju in Chungbuk, Cheonan in Chungnam Province, Pohang in Gyeongbuk Province, Yeongdo in Busan, and Seogwipo in Jeju Island. The selected cities will recover from stagnant functions of community and promote local resident's cultural lives. Particularly, it is anticipated to expand tourism and cultural industry by developing cultural assets in distinctive regions into global brands. Accordingly, this study derived 4P (Place, Product, People, Promotion) suitable for city branding analysis and analyzed each city's current branding, based on the regional marketing and city brand theory. Furthermore, this study proposed to improve city's future cultural activities by presenting a city branding evaluation measurement model. The research results are described below. First, culture city's brand identity is more effective when it is clear and differentiated. Second, contents development scenario that provides culture city's specialized and unilateral experience is necessary. Third, digital storytelling focused on differentiated $4 \mathrm{P}$ factors and essential target needs to be sustainable. This study is intended to provide a new guideline for cultural city branding activities that revitalize the region.
\end{abstract}

Keywords: City Branding, Cultural City, Regional Marketing, 4P

요약: 도시브랜딩은 도심재생 및 도시경쟁력 확보를 위한 시대적 요청이다. 최근 정부에서는 전략적 도시브랜딩을 위해서 전국에서 1차 법정문화도시로 7 개 도시를 선정했다. 경기 부천, 강원 원주, 충북 청주, 충남 천안, 경북 포항, 부산 영도구, 제주 서귀포이다. 선정된 문화도시 는 침체된 도심과 공동체 기능을 회복하고 지역주민의 문화적 삶을 증진하게 된다. 특히, 예 술, 역사전통, 문화산업 등 특색있는 지역의 문화자산을 세계적인 브랜드로 키워 관광산업, 문 화창업을 견인하는 역할을 할 것으로 기대되고 있다. 이에 본 연구는 기존의 지역마케팅과 도 시브랜드 이론을 바탕으로 문화도시브랜딩 분석에 적합한 4P(Place, Product, People, Promotion)를 
새롭게 도출하여 각 문화도시의 도시브랜딩 사례와 현황을 분석하였다. 또한, 도시브랜딩 평 가측정모형을 제시함으로써 향후 문화도시활동의 프로세스를 개선할 수 있도록 제안하였다. 연구결과는 다음과 같다. 첫째, 문화도시만의 브랜드 아이덴티티가 차별화되고 명확할수록 효 과적이다. 둘째, 문화도시만의 일관된 경험을 제공하는 콘텐츠 개발 시나리오가 필요하다. 셋 째, 핵심 타깃과 차별적 $4 \mathrm{P}$ 요소를 중심으로 선형적이거나 비선형적인 디지털스토리텔링이 지 속가능해야한다. 이번 연구가 지역을 활성화하고 삶의 질을 향상시키는 문화도시 브랜딩 활동 에 새로운 기준점과 가이드라인이 될 수 있기를 기대한다.

핵심어 : 도시브랜딩, 문화도시, 지역마케팅, $4 \mathrm{P}$, 평가모형 측정

\section{1. 서론}

\section{1 연구배경 및 목적}

문화체육관광부는 2019년 12월, 1차 법정문화도시 7곳을 확정하였다. 문화도시는 지역문화진흥법에 따라 지역별로 특색 있는 문화자원을 효과적으로 활용해 문화 창조력을 강화할 수 있도록 지정된 도시이다. 정부는 2022년까지 약 30개의 문화도시를 선정해 고령화와 산업구조 변화로 위기에 처한 지역을 부흥하고자 한다. 1 차 법정문화도시로 선정된 7개 도시는 경기 부천, 강원 원주, 충북 청주, 충남 천안, 경북 포항, 부산 영도구, 제주 서귀포이다. 이 도시들은 2020년 14억원을 시작으로 향후 5년간 최대 100 억원의 재정지원을 받아 침체된 도심과 공동체 기능을 회복하고 지역주민의 문화적 삶을 증진하게 된다. 특히, 예술, 역사전통, 문화산업 등 특색 있는 지역의 문화자산을 세계적인 브랜드로 키워 관광산업, 문화창업을 견인하는 역할을 할 것으로 기대되고 있다.

도시브랜딩은 도시재생 및 도시경쟁력 차원에서 필요하며 시민들의 문화체험과 삶의 질 향상에도 크게 영향을 미친다. 특히, 브랜딩 차원에서 유무형의 자산을 개발하고 이를 디지털 미디어를 통해 사용자들 사이에서 활발하게 공유하고 확산할 수 있도록 기획하고 실행하고 있는 상황이다. 본 연구는 이러한 상황에 주목하고 문화도시활성화를 위한 도시브랜드 전략과 실행을 살펴보고자 한다. 정부의 정책기조와 연계된 문화도시 활동을 기초로 도시브랜딩의 실제적인 사례를 분석함으로써 이론적 연구와 실무적 함의를 도출하는데 기여하고자 한다.

\section{2 연구범위 및 방법}

본 연구는 문화도시의 브랜딩 사례를 분석하기 위해 각 도시의 브랜딩 대표 사례를 수집하고 관련된 국내외 사례, 문헌, 연구보고서 및 통계자료를 토대로 활용하고자 한다. 이론적으로는 사이몬 안홀트(Simon Anholt)의 도시브랜딩 이론을 비롯한 다양한 도시브랜드 이론을 근거로 문화도시의 브랜딩 방안을 연구한다. 특히, Ikuta, Yukawa and Hamassaki의 도시지역브랜드와 사이몬 안홀트의 브랜드 육각모델을 바탕으로 문화도시의 커뮤니케이션을 위한 4가지 핵심요소를 새롭게 도출하고자 한다. 4가지 핵심요소를 4P(Promotion, Product, Place, People)로 규정하고 네 가지 차원에서 문화도시 융성을 위한 다양한 활동을 분석하고자 한다. 프로모션(Promotion)은 지역축제, 페스티벌, 컨퍼런스 
등의 활동이며, 상품(Product)은 특산품, 대표상품을 포함한다. 장소(Place)는 관광명소, 특화 길거리 등이며, 사람(People)은 지역출신 유명인, 인플루언서, 지역 일반인을 의미한다. 각 문화도시의 브랜드전략과 실행을 $4 \mathrm{P}$, 핵심타깃, 핵심자원, 콘텐츠키워드, 콘텐츠시나리오 등의 기준으로 분석하고 향후 도시브랜드전략의 가이드라인을 제시 하고자 한다.

\section{2. 도시브랜딩의 이론적 배경}

\section{1 도시브랜드의 고찰}

\subsection{1 도시브랜드 개념}

도시브랜드의 개념은 도시의 경쟁력 확보를 위해서 도시에 대한 연구와 도시브랜딩 정책을 실행하면서 발생하였다. 우리나라의 경우 1990년대 지자체 실시 이후 정부주도로 도시경쟁력을 강화하고 도시브랜드를 적극적으로 개발하기 위해 도시브랜드 마케팅에 집중하기 시작했다. 도시브랜드는 도시가 지니는 다양한 환경, 기능, 시설, 서비스 등에 의해 다른 도시와 구별되도록 하는 활동으로 정의할 수 있다. 도시브랜드는 도시의 개성을 창조하는 것으로 도시를 경험 하고자 하는 소비자들에게 강한 인식을 갖도록 하는 일련의 도시마케팅 활동이라고 할 수 있다[1].

\subsection{2 도시브랜드의 구성요소}

도시브랜딩을 위한 구성요소는 브랜드 비전, 브랜드 콘셉트, 브랜드 개성, 브랜드 네임, 브랜드 슬로건 등 언어적인 요소와 함께 로고, 캐릭터, 상징물 등 시각적인 요소로 구성된다. 또한, 도시에 거주하는 주민을 비롯하여, 기업인, 관광객, 투자자, 등 수많은 이해관계자가 존재하며 도시기본계획이나 지역개발계획 등도 도시브랜드에서 중요한 요소 중 하나이다. 이에 따라 도시브랜드의 구성요소를 아래의 표와 같이 살펴볼 수 있다[2].

[표 1] 도시브랜드 구성요소[3]

[Table 1] City Brand Components

\begin{tabular}{|c|c|c|}
\hline \multicolumn{2}{|c|}{ 요소 } & 정의 \\
\hline 언어적 요소 & 도시브랜드 핵심수단 & $\begin{array}{l}\text {-도시의 핵심적 정체성 표상 } \\
\text {-브랜드 아이덴티티(CI,BI) }\end{array}$ \\
\hline 시각적 요소 & 커뮤니케이션 & -도시의 정체성을 전달하는 도시판촉 \\
\hline \multirow{2}{*}{ 도시의 행동양식 } & 주체 & $\begin{array}{c}\text {-도시의 생산자이자 소비자인 이해관계자의 } \\
\text { 역할과 태도 }\end{array}$ \\
\hline & 목표집단 & $\begin{array}{c}\text {-도시를 방문하여 장소를 소비하고 투자활동하는 } \\
\text { 소비자로 주민을 포함 }\end{array}$ \\
\hline \multirow{4}{*}{ 환경물과 서비스 } & 물리적 브랜드 & -상징으로서 도시경관과 브랜드경관 \\
\hline & 물리적 지지자 & -기능으로서 도시 인프라 \\
\hline & 관련 서비스 & $\begin{array}{c}\text {-도시의 환대, 서비스산업, 고용과 혁신을 제공 } \\
\text { 해주는 도시의 첨단, 지식, 문화산업 }\end{array}$ \\
\hline & 이미지와 자산가치 & $\begin{array}{c}\text {-브랜드로서 도시에 대한 소비자의 인지의 발전단계 } \\
\text { 및 그 가치를 표현하는 도시브랜드 자산 등 }\end{array}$ \\
\hline
\end{tabular}




\section{2 도시브랜딩의 이론}

도시브랜딩에 대해서는 국내외에 다양한 정의와 함께 이론적인 연구가 진행되었다. 장소마케팅, 도시마케팅, 도시브랜딩의 용어를 통해 논의되었다. 본 연구에서는 도시브랜드에 대한 논의가 본격화된 2000년대 중반부터 현재까지의 주요 이론을 중심으로 살펴본다.

\subsubsection{Dooley \& Bowie : Place Brand Architecture(2005)}

둘리와 보위의 장소브랜드아키텍처 연구에서는 제품 및 서비스 브랜드, 지역 및 도시브랜드, 산업브랜드, 국가브랜드, 초국가브랜드 순서로 상위로 위계화된다[4]. 또한, 각 브랜드들은 서로 연관성을 지니며 상호작용한다. 즉, 제품 브랜드가 산업브랜드나 국가브랜드에 영향을 미치며, 반대로 산업브랜드나 국가브랜드가 제품 브랜드에 영향을 미치기도 한다는 의미이다. 예를 들어, 롤렉스라는 제품브랜드는 스위스 시계 산업 및 스위스 라는 국가브랜드에 영향을 미치며, 스위스라는 국가브랜드는 스위스에서 생산되는 개별 제품 브랜드에 긍정적인 영향을 미치게 된다. 이처럼, 장소브랜드아키텍처는 상업브랜딩에서 태어난 개념이다. 그리고, 브랜드 포트폴리오를 디자인하고 관리하는데 사용되며 각 브랜드에 목적, 관련성 및 명확성을 제공한다. 이 연구는 장소브랜드아키텍처를 설계, 관리, 해석하는 관련된 요인을 보여주고 있다.

\subsubsection{Ikuta, Yukawa and Hamassaki의 일본 12개 도시브랜딩 연구(2007)}

이쿠타 외 2 인의 연구는 지역 브랜딩을 위해 노력한 일본의 12 개 주요 도시의 사례 연구를 제시하고 있다[5]. 주제별, 목적별, 지역별 도시이미지의 차이를 분석함으로써 지역별 이미지, 개별 브랜드 통합 패턴, 지역별 이미지 측정, 개별 브랜드 파급 패턴의 4 가지 유형으로 구분하고 있다. 특히, 도시지역브랜드를 구성하는 핵심요소로서 도시지역상품, 경관, 투자관광, 인적자원, 지역주민 등을 제시하고 있다. 이들의 연구에서는 기업 브랜딩과 달리 지역 브랜딩의 핵심적인 문제는 다양한 정책 실행 및 실무자의 참여를 꼽고 있다. 즉, 다양성이 증가할수록 지역 브랜드를 통제하는 지방 정부의 조치가 더 어려워지고 이는 곧 효율성 감소로 이어질 수 있다고 지적한다. 지역 브랜딩을 시행할 때 이러한 문제는 지역 브랜드를 공식화할 목적으로 지역 자원을 명확히 하고 네트워크를 만드는 등 지역 브랜드 자체에 대한 연구가 수반되어야 한다.

\subsubsection{Kavaratzis \& Ashworth의 도시브랜딩 연구(2006)}

카바라치스와 애시워드의 도시브랜딩 연구는 두 가지 커뮤니케이션 관점에서 정리하고 있다[6]. 도시브랜딩의 첫 번째 커뮤니케이션은 환경전략(Landscape Strategies), 행동(Behavior), 조직적 구조(Organizational Structure), 인프라(Infrastructure) 차원의 커뮤니케이션이다. 그리고 두 번째 커뮤니케이션은 광고, $\mathrm{PR}$, 그래픽디자인, 슬로건 등이다. 즉, 도시를 구성하고 있는 실체적 커뮤니케이션과 도시의 상징적 커뮤니케이션 으로 구분하여 도시브랜딩 전략을 제시하고 있다. 이들의 연구는 두 가지 커뮤니케이션을 통해서 도시의 이미지 커뮤니케이션이 통합되며 이는 곧 도시이미지로 귀결된다고 밝힌다. 즉, 아이덴티티- 포지셔닝 - 이미지의 흐름으로 도시브랜드 전략을 구축할 수 있으며 도시이미지형성이 결국 장소커뮤니케이션과 직결된다고 제시하고 있다.

\subsubsection{Molianen \& Rainisto의 도시브랜딩 연구(2009)}


몰리아닌과 라니스토의 연구는 마케팅적 지식을 결합하여 장소마케팅의 성공 요인에 대해 3 개의 차원으로 구성된 기본프레임워크를 구축하였다[7]. 이 연구에 따르면, 첫 번째 차원인 장소마케팅 과정의 필수적인 과정은 6가지(그룹계획, 비전과 전략, 분석, 정체성과 이미지 설정, 민관 협력, 리더십)로 구성되어 있고 두 번째 차원인 경쟁적 상황의 4가지 요소(정치적 통일성, 글로벌 시장, 지역개발, 과정의 일치성)를 정의하였다. 세 번째 차원은 실제 마케팅을 진행하는 전략적 이용, 조직력, 존재감, 측정과 후속조치로 이루어져 있다. 이는 장소마케팅을 위해 상호작용한다.

\subsubsection{Parkerson과 Saunders의 도시브랜딩 연구(2005)}

파커슨과 손더스는 Jafari(1982)의 여행세분화모델을 기반으로 정치적 차원이라는 변인을 포함시켜 도시브랜드 모델을 제안하였다[8]. 이 모델은 도시를 유형요소와 무형요소로 나누고, 주요 공중을 도시내부자와 외부자 관점에서 보아야 한다고 주장하였다. 뿐만 아니라 소비자들 간에 유형요소와 무형요소에 대한 중요도를 다르게 인식하는 점에 초점을 맞췄다. 예를들어 방문자들은 방문 도시를 선정하는데 도시의 유형적 자산 요소 중에서 문화, 예술, 역사, 쇼핑 등에 우선순위를 부여한다는 것이다. 그러나 도시에서 일상적인 생활을 하는 시민들은 교육, 건강, 주거, 고용, 기반시설 등에 우선 순위를 둔다.

\subsubsection{M2S Wheel 프레임워크}

도시브랜딩을 위한 프레임워크는 랜드마크 베이스의 4M2S로 정리된다[9]. 4M은 Magnus(거대적 요소), Miracle(기적적 요소), Merriment(유희적 요소), Meaning(의미적 요소)이고 $2 \mathrm{~S}$ 는 Symbol, Story이다. 이러한 속성적 요소들은 경외감, 놀라움, 즐거움, 감동으로 이어지는 감성적 가치와 연결된다. 그리고 물리적인 놀라움에서 의미적인 감동을 전달하는 방향으로 발전하게 된다.

\subsubsection{Simon Anholt의 도시브랜드 육각모델}

사이몬 안홀트는 도시브랜드 지수측정을 위해 6각형 모델을 제시하였고 구체적인 항목으로 6P를 제안하였다[10]. 6P는 Presence(존재감), Place(장소), Potential(잠재력), Pulse(역동성), People(인적자원), Prerequisites(기본요건)이다.

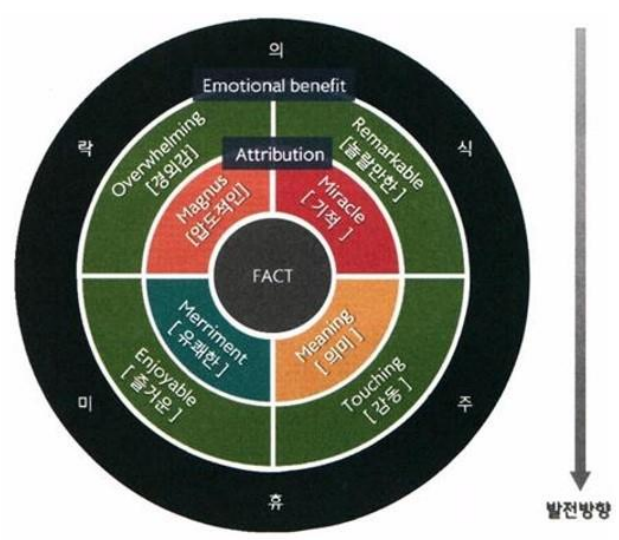

[그림 1] 4M2S 프레임워크

[Fig. 1] 4MS Framework 


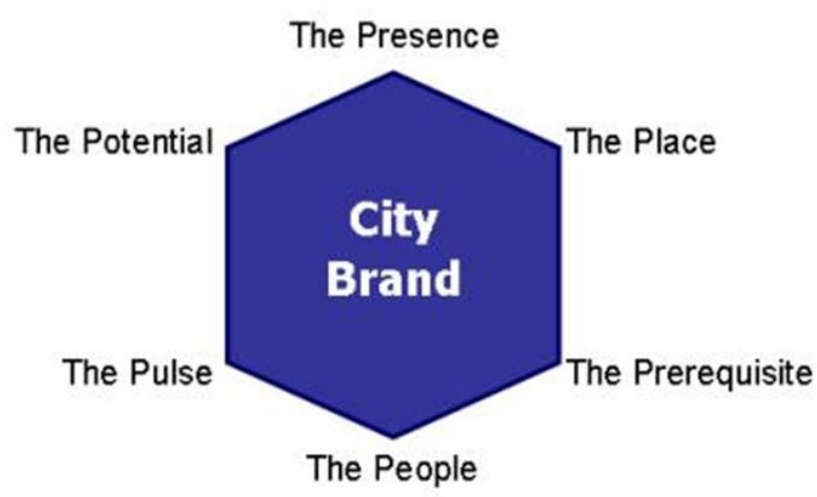

[그림 2] 사이먼 안홀트 도시브랜드 6각형 모델

[Fig. 2] Simon Anholts' City Brand Hexagon Model

\section{7개 문화도시의 브랜딩 사례분석}

\section{1 문화도시브랜딩의 $4 \mathrm{P}$}

본 연구에서는 기존의 도시브랜딩 이론을 바탕으로 문화도시활성화에 적합한 도시 브랜딩 핵심요소를 도출하고자 한다. 따라서, 이론적 배경에서 밝힌 도시브랜드이론 중에서 사이몬 안홀트(Simon Anholt)의 6P와 Ikuta, Yukawa \& Hamassaki(2007)의 이론을 바탕으로 문화도시활성화를 위한 도시브랜딩 핵심요소 $4 \mathrm{P}$ 를 도출한다. 사이몬 안홀트의 장소(Place), 사람(People)와 Ikuta 등의 사람(People), 장소(Place), 상품(Product)을 중심으로 4P는 Promotion(지역축제), Product(대표상품), Place(지역명소), People(지역사람)이다. 이는 보다 세부적으로 다음의 [표 2]와 같이 정의할 수 있다. 아래의 $4 \mathrm{P}$ 를 핵심요소로 7 개 문화도시의 브랜딩 사례를 분석하고자 한다.

[표 2] 문화도시브랜딩의 $4 \mathrm{P}$

[Table 2] 4P of Culture City Branding

\begin{tabular}{|c|c|c|}
\hline 4P & 정의 & 목적 \\
\hline Promotion & 지역축제, 페스티벌, 컨퍼런스, 이벤트 & 도시의 주체로서 참여하고 경험하는 기회 제공 \\
\hline Product & 특산물, 대표상품 & 대표상품을 통한 도시정체성의 공유 \\
\hline Place & 관광명소, 특화길거리, 도시디자인 & 장소가 지닌 개성, 인상, 추억 등을 제공 \\
\hline People & 지역주민, 지역인플루언서, 지역출신 유명인 & 지역사람들과의 소통, 교감, 관계 형성 \\
\hline
\end{tabular}

\subsection{7 개 문화도시의 브랜딩 사례}

\subsection{1. 문화도시 원주 $4 \mathrm{P}$ 분석}


원주의 도시브랜딩은 4P중에서 Product(지역제품)가 중심이 되고 있다는 점을 발견할 수 있다. 지역의 문화유산인 한지를 다각도로 활용하고 있다는 점이 가장 큰 특징이다. 한지를 통해서 사람들의 경험과 체험을 끌어내고 있다. 핵심타깃은 3040여성으로 두고 유아, 어린이를 자녀로 둔 핵심타깃이 가족단위로 한지 체험을 할 수 있는 프로그램을 제공하고 있다. 구체적으로 한지 등불, 한지 소원종이, 한지 핀 만들기, 한지 드림캐쳐, 한지 박물관, 기념품 샵, 석고방향제, 페이스페인팅 등 다양한 한지 체험을 할 수 있다. 또한, 한지로 만들 수 있는 다양한 키트를 제공하고 작품을 만들 수 있는 방법을 유튜브 영상을 통해 공유함으로써 누구나 가정에서 한지를 손으로 만지며 제작할 수 있었다.

특히, 소셜미디어를 이용하는 아이가 있는 $30 \sim 40$ 대 여성을 타깃으로 설정하였고 아이가 있는 엄마들은 카카오톡 단체 채팅방이나 주기적인 모임이나 등 참여하고 공유할 확률이 높으므로 정보 공유가 활발하고 긍정적인 입소문의 영향으로[11] 빠르게 콘텐츠를 확산할 수 있다.

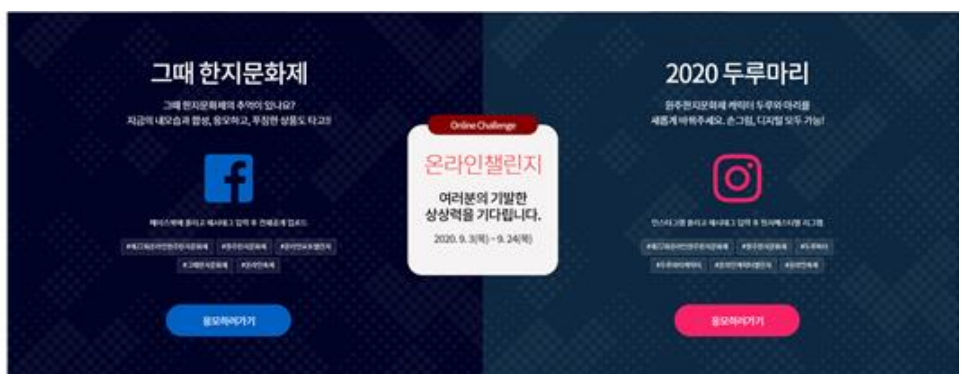

[그림 3] 소셜미디어를 통한 원주 한지문화제

[Fig. 3] Wonju Hanji Culture Festival through Social Media

\subsection{2. 문화도시 부천 $4 \mathrm{P}$ 분석}

부천의 도시브랜딩은 4P중에서 Promotion(지역페스티벌)이 중심이라는 점을 발견할 수 있다. 영화, 만화, 애니메이션, 비보이등 확실한 매니아층을 핵심타깃으로 삼고 공감대와 자발적 공유를 유도하고 있다는 점이 가장 큰 특징이다. 부천은 부천국제 판타스틱영화제(BIFAN), 부천국제만화축제(BICOF), 부천세계비보이대회(BBIC)가 대표 Promotion이다.

BIFAN의 경우, 타겟에 대한 높은 이해를 바탕으로 유대감을 형성 할 수 있는 고객 지원 서비스를 운영하여 컨텐츠의 양과 질을 높이고, 'e판타캡션' 이라는 최첨단 자막 시스템 도입으로 관객에게 techperience를 제공하고 있다. 또한, OTT 서비스와의 독립적인 계약으로 자사 사이트로의 유입률과 매출이 큰 폭으로 증대하는 성공적인 결과를 얻고 있다. 물론 이러한 서비스들은 온라인결제시스템의 지원과도 연관성이 있다[12].

그리고, 일회성 행사로 끝나지 않는 연속성 있는 세계적인 축제를 고안하여, 도시의 브랜드 정체성을 확립했으며, YOUTUBE, 페이스북, 인스타그램, V LIVE, WATCHA등 가능한 모든 소셜미디어를 통해 소통하며 대중의 참여를 끌어내고 있다. 그리고 코로나19라는 위기 속에서 오프라인으로만 가능한 축제라는 고정관념을 탈피한 부천의 새로운 시도는 소셜 기능을 활용한 도시마케팅의 우수 사례이다. 구체적으로 무관중 온라인 비보이 대회, 온라인 영화제 등이 있다. 


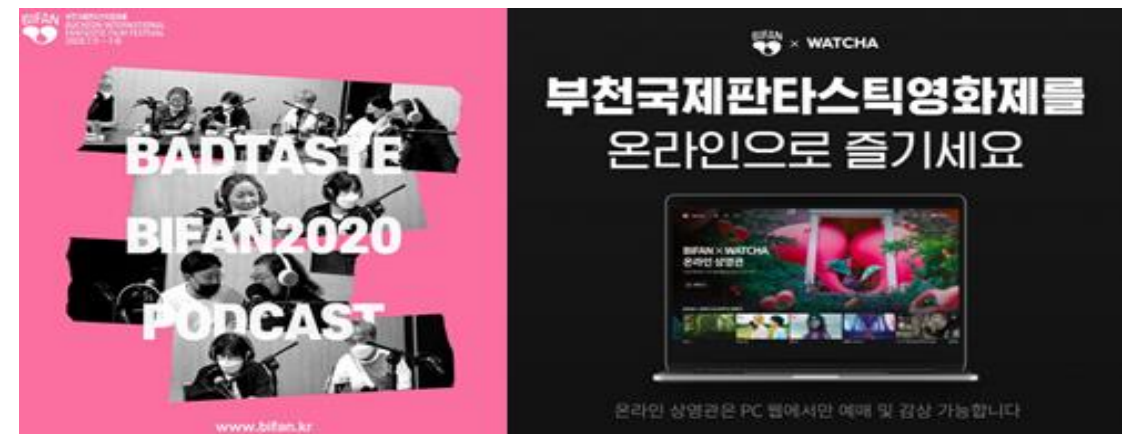

[그림 4] 온라인으로 진행된 부천국제영화제

[Fig. 4] Bucheon International Film Festival Online

\subsection{3. 문화도시 부산 영도구 $4 \mathrm{P}$ 분석}

부산 영도의 도시브랜딩은 $4 \mathrm{P}$ 중에서 $\mathrm{Place}($ 지역명소)가 중심이라는 점을 발견할 수 있다. 전통적 명소인 태종대, 영도다리 뿐만 아니라 최근 20 대의 필수여행코스로 손꼽히는 흰여울문화마을, 깡깡이예술마을이 대표적인 지역명소이다. 부산영도구는 근대 조선소, 동삼동 패총, 한국전쟁 피난지라는 지역의 역사와 특성을 살려서 도시재생을 성공적으로 이루었다는 점이 가장 큰 특징이다.

깡깡이 예술마을은 근대 조선산업의 유산과 그에 얽힌 풍부한 이야기를 담은 공공 예술작품을 곳곳에 설치하고, 생활문화센터를 만들어 마을 동아리를 활성화하는 등 도시 재생사업을 추진하였다. 특히, 수많은 문화예술인들이 참여해 창의적인 아이디어를 바탕으로 지역주민, 공공기관과 협력해 역사와 이야기를 지닌 아름다운 마을로 탈바꿈시켜 모범적인 도시재생모델이 되었다. 낡고 오래된 건물들에 그린 벽화는 녹지가 부족한 마을에 자연의 생기를 더해주고 있는데 벽화 작품들의 소재가 친숙하여 마케팅이나 디자인 관점에서 돋보이는 작품들이다.

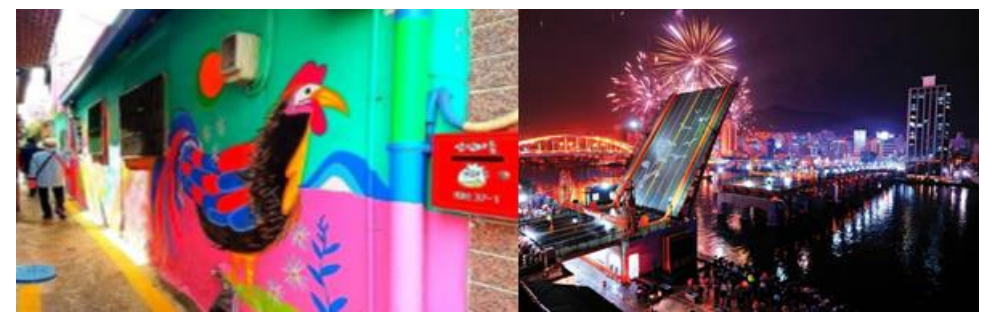

[그림 5] 깡깡이 예술마을과 영도다리 야경

[Fig. 5] KangKang Art Village and Yeongdo Bridge Night View

\subsection{4. 문화도시 제주 서귀포 $4 \mathrm{P}$ 분석}

제주 서귀포의 도시브랜딩은 4P중에서 People(지역사람)이 중심이라는 점을 발견할 수 있다. 서귀포시는 105 개 마을사람들이 가꾸는 노지문화를 핵심콘텐츠로 삼고 서귀포 시민들이 콘텐츠의 생산자로 활동하고 있다는 점이 가장 큰 특징이다. 구체적으로 ‘노지문화'를 가꾸기 위해 마을 주민, 지역 작가, 미래 세대 등 다양한 분야에서 2 만여명의 시민들이 170 여개의 문화 도시 프로그램에 참여하며 시민들이 문화 향유 활동을 통한 문화 소비자뿐만 아니라 노지 문화를 발굴하고 콘텐츠를 직접 창작해보는 
문화 생산자의 역할을 수행한다.

이처럼, 서귀포 시민들이 만들어가는 일상의 이야기가 콘텐츠가 된다. 105 개 마을이 지닌 신화 이야기, 민요, 제주어, 돌하르방, 바람, 물, 바다, 돌, 감귤, 해녀, 용천수, 오름, 옹기, 올레 등을 콘텐츠화 하여 도시 브랜딩 마케팅에 활용하고 있다. 이러한 콘텐츠를 활용해 마케팅을 진행 중인데 \#노지문화 \#노지알지백오가지 처럼 해시태그를 노출하고 있으며 \#제주어 이모티콘도 인기이다. 이처럼 소셜미디어를 통한 정보기술의 발달로 정보공유가 더 쉬워지고 있음을 알 수 있다[13].

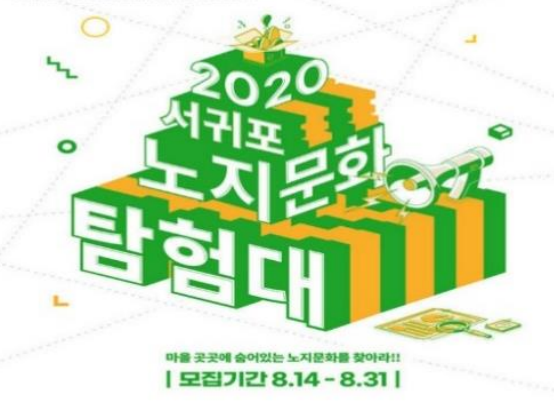

[그림 6] 서귀포 노지문화 탐험대 모집광고

[Fig. 6] Seogwipo Noji Culture Expedition Recruitment Advertisement

\subsection{5. 문화도시 청주 $4 \mathrm{P}$ 분석}

청주의 도시브랜딩은 4P중에서 Promotion(지역페스티벌)이 중심이라는 점을 발견할 수 있다. 청주는 유네스코 문화유산이자 세계적인 인쇄활자인 직지를 중심으로 국제적인 페스티벌을 펼치고 있다. 직지의 스토리텔링을 통해 경험마케팅을 이뤄내고 있다는 점이 가장 큰 특징이다. 최근에는 전시산업이 고부가가치 산업으로 발전하기 때문이다[14].

청주는 2003년부터 직지축제를 개최하였으나, 직지의 가치를 세계적으로 알리는데 한계를 느끼고, 유네스코 직지상 시상식과 직지축제를 통합해 국제행사로 발전시켰다. 직접적 홍보보다 다양한 전시와 체험들을 통해 소비자가 직지를 체험할 수 있도록 행사의 형태를 변화하였고 단기성으로 끝나기 쉬운 행사장소를 주변 상권까지 포함하여 벽화를 그려서 관심콘텐츠를 검색해 볼 수 있도록 하였다. 청주에서 문화자원으로 홍보하고 있는 직지심체요절은 사실 청주에 보유하고 있지 않다. 수많은 근거자료와 기록으로 인정을 받아 유네스코 등록을 한국에서 완료하였고 실체가 한국에 있지는 않지만 많은 학습과 자료를 통해 어린이 관객에게 한국의 기술력을 체험하도록 유도하고 있다.

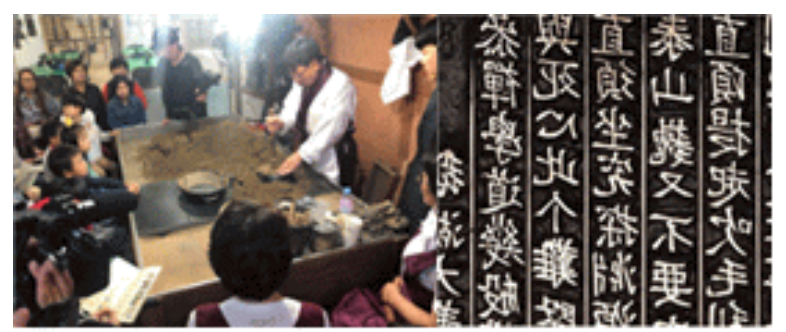

[그림 7] 어린이 직지체험교실과 직지인쇄본

[Fig. 7] Children's Jikji Experience Classroom and Jikji Print 


\subsection{6. 문화도시 포항 $4 \mathrm{P}$ 분석}

포항의 도시브랜딩은 4P중에서 Place(지역명소)가 중심이라는 점을 발견할 수 있다. 포항은 울릉도를 제외하면 한반도에서 가장 먼저 해가 뜨는 곳이다. 호미곶 해맞이광장, 영일대해수욕장 등 해돋이 명소를 관광콘텐츠화하여 차박 캠핑, 요트 등의 라이프스타일을 제안한 점이 특징이다.

호미곶에 가면 새천년 기념관, 바다 화석박물관,수석박물관을 볼 수 있고 가장 유명한 상생의 손 조형물이 2 개가 있는데 사용자들의 인스타그램에 가장 많이 올라오는 풍경이다. 포항은 옛 삼국유사에 있는 연오랑세오녀 설화 이야기를 바탕으로 한 문화공간인 연오랑세오녀테마공원을 운영 중이다. 특히 세오가 짠 비단을 보관했던 창고인 귀비고를 포항시민과 관광객을 위한 문화창고로 재탄생 시키는 등 Place적인 요소를 적극 활용하고 있다. 또한, 귀비고에서는 스토리텔링적인 요소와 미디어 요소를 더하여 젊은 타깃에게 힐링공간을 제공하고 있으며 SBS 드라마 '동백꽃 필 무렵' 및 $\mathrm{JTBC}$ 드라마 '런 온' 주요 촬영지여서 외국인 관광객 급증하고 있다. 이처럼 대중문화가 도시의 이미지에 미치는 영향이 크게 나타났다[15].

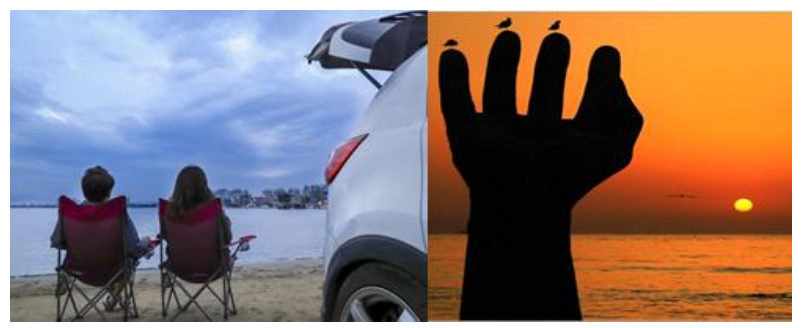

[그림 8] 포항차박캠핑과 상생의 손 조형물

[Fig. 8] Pohang Car Camping and Win-win Hand Sculpture

\subsection{7. 문화도시 천안 $4 \mathrm{P}$ 분석}

천안의 도시브랜딩은 4P중에서 People(지역사람)가 중심이라는 점을 발견할 수 있다. 천안은 시민들의 작은 창작 활동에 주목했다. 일상에서 시민들이 만드는 작은 소모임이 하나의 문화생태계로 네크워킹되어 독립된 건강한 문화공동체를 만들어나간다는 점이 가장 큰 특징이다. 그리고 일반인 창작자를 보호하기 위해 프리랜서 협동조합을 구성함으로써, 일반인 창작자들의 권리보호와 사회 안전망을 구축하고 이들의 경쟁력을 강화한다는 점도 좋은 모델이다. 전체적으로 천안은 LINK라는 4대 브랜딩 전략을 실행하고 있다. 구체적으로, L(life)일상속 취향의 발견, I(identification)문화적 실천과 가능성의 실현, $\mathrm{N}$ (navigation)문화산업 생태계 조성, $\mathrm{K}$ (kintting) 천안발 문화나들목 구축이다. 뿐만 아니라 사회적 자본구축 및 지역문제해결을 위한 사회적기업을 육성하고 있다.

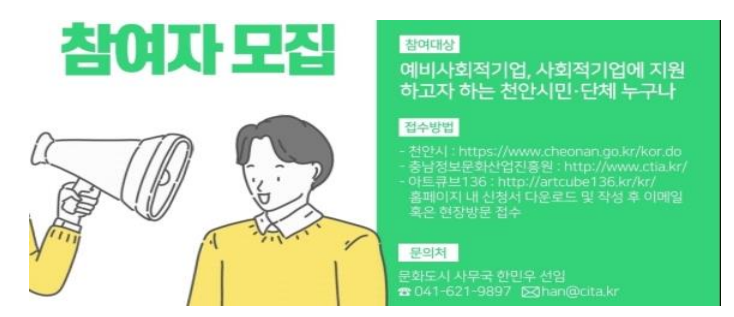

[그림 9] 천안의 사회적기업 지원모집

[Fig. 9] Cheonan Social Enterprise Support Recruitment 


\section{4. 연구결과}

\section{1 문화도시브랜딩의 분석 결과}

7 개 문화도시의 브랜딩 전략과 활동내용을 분석한 결과, 각 문화도시마다 누구에게 (WHO), 무엇을(WHAT), 어떻게(HOW)라는 공통적인 커뮤니케이션 프레임속에서 각 도시의 지역적 특성을 고려한 차별점을 찾을 수 있었다. 각 문화도시의 공통점은 콘텐츠 개발에 집중하고 있다는 점이며 차별점은 핵심타깃과 $4 \mathrm{P}$ 중 핵심요소가 각각 다르다는 점이다. 그 내용을 아래의 [표 3]으로 정리할 수 있다. 그리고, 콘텐츠 측면에서 살펴보면, [표 4]와 같이 7개 문화도시 브랜딩에서 각각의 차별화된 콘텐츠 키워드와 콘텐츠 시나리오가 나타났다. 이는 커뮤니케이션 프레임의 타깃, 4P, 핵심전략을 바탕으로 구성되었음을 알 수 있다.

[표 3] 7개 문화도시의 커뮤니케이션 프레임

[Table 3] Communication Frames in Seven Cultural Cities

\begin{tabular}{|c|c|c|c|}
\hline \multirow{2}{*}{ 문화도시 } & 누구에게 & 무엇을 & 어떻게 \\
\cline { 2 - 4 } & 핵심타깃 & $4 \mathrm{P}$ & 핵심전략 \\
\hline 원주 & 3040 여성 & Product & 한지의 자산화 \\
\hline 부천 & 문화매니아 & Promotion & 축제도시화 \\
\hline 부산영도 & $\mathrm{MZ}$ 세대 & Place & 구도심 재생 \\
\hline 서귀포 & 중장년층 & People & 주민들의노지문화 \\
\hline 청주 & 어린이, 학생 & Promotion & 문화유산체험 \\
\hline 포항 & 가족 & Place & 라이프스타일 제안 \\
\hline 천안 & 문화생산자 & People & 문화생태계 \\
\hline
\end{tabular}

[표 4] 7개 문화도시의 콘텐츠 키워드 및 시나리오

[Table 4] Content Keyword and Scenarios in Seven Cultural Cities

\begin{tabular}{|c|c|c|}
\hline 문화도시 & 콘텐츠 키워드 & 콘텐츠 핵심 시나리오 \\
\hline 원주 & 신기한종이 & 종이가 들려주는 백가지 신기한 이야기 \\
\hline 부천 & 일상문화 & 영화, 만화, 춤이 주는 일상의 즐거움 \\
\hline 부산영도 & 예술골목 & 바닷가에서 예술의 골목을 걷다 \\
\hline 서귀포 & 노지문화 & 105 개 마을 사람들이 만드는 노지문화 \\
\hline 청주 & 유산체험 & 내 마음대로 즐기는 문화유산체험기 \\
\hline 포항 & 뉴라이프 & 해돋이와 함께 즐기는 우리가족 라이프스타일 \\
\hline 천안 & 문화독립 & 시민의 문화활동을 통한 자립적 문화생태계 \\
\hline
\end{tabular}

\section{2 문화도시브랜딩 평가모형 도출}

본 연구에서는 7 개 문화도시브랜딩의 분석결과를 바탕으로 [그림10]의 문화도시브랜딩 평가모형을 제안한다. WHO, WHAT, $\mathrm{HOW}$ 의 축에서 핵심타깃, $4 \mathrm{P}$ 콘텐츠, 핵심전략을 구성할 수 있다. 그리고 [표 5]와 같이 세 가지 축을 중심으로 문화도시브랜드 평가측정을 위한 12 개 주요항목을 구성할 수 있다. 예를들어 척도구성을 한다면 안홀트 도시브랜드지표 
(Anholt City Brands Index)처럼 도시 브랜드 평가기준이 될 수 있다. 그리고 향후 이를 바탕 으로 보다 세밀한 평가항목을 개발할 수 있다. 또한, 창의도시의 브랜드 아이덴티티의 요소를 6 개 차원, 27 개 요소로 도출한 연구도 의미있는 사례이다. 6 개 차원은 사회·공익, 도시자원, 도시기획, 과학기술, 문화창의, 프로모션이며 27개 요소는 문화예술, 디자인, 창조문화산업, 콘텐츠, 이벤트, 커뮤니케이션, 교육, 문화시설, 건축, 관광·미식, 자연환경, 전통, 라이프스타일, 웰빙, 인간중심, 공공의식, 사회안전, 사회활동, 서비스, 도시계획, 친환경, 융합, 국제화·다문화, 디지털, 첨단과학, 자동화, 가치창출 등 이었다[16].

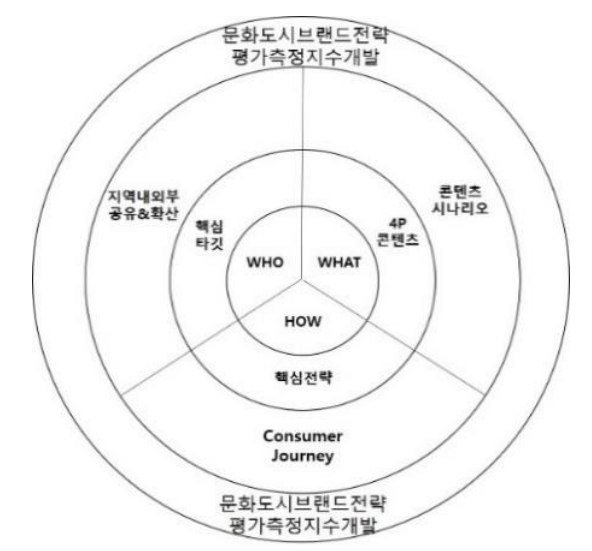

[그림 10] 문화도시브랜드전략 평가모형

[Fig. 10] Culture City Brand Strategy Evaluation Model

[표 5] 문화도시브랜드 평가 주요항목

[Table 5] Major Items for Evaluation of Culture City Brand

\begin{tabular}{|c|c|c|}
\hline 문화도시 & $\begin{array}{c}\text { 평가측정지수개발을 위한 } \\
12 \text { 개 주요항목 }\end{array}$ & 12 개 평가항목 \\
\hline WHO & $\begin{array}{c}\text { 핵심타깃 설정 } \\
\text { 2차타깃 설정 } \\
\text { 지역내부 커뮤니케이션 방안 } \\
\text { 지역외부 커뮤니케이션 방안 }\end{array}$ & $\begin{array}{c}\text { 핵심타깃이 명확한가 } \\
\text { 2차 타깃이 설정되었는가 } \\
\text { 지역주민의 공감과 참여 방안이 구체적인가 } \\
\text { 지역외부의 지지와 협력 방안이 구체적인가 }\end{array}$ \\
\hline WHAT & $\begin{array}{c}4 \mathrm{P} \text { 의 조직적 구성 } \\
4 \mathrm{P} \text { 중 핵심콘텐츠 설정 } \\
\text { 콘텐츠 키워드 도출 } \\
\text { 콘텐츠 시나리오 설정 }\end{array}$ & $\begin{array}{c}\text { 4P가 균형있게 구성되어 있는가 } \\
\text { 핵심요소가 설정되어 있는가 } \\
\text { 콘텐츠 키워드가 짧고 명확한가 } \\
\text { 콘텐츠의 시나리오가 구성되었는가 }\end{array}$ \\
\hline HOW & $\begin{array}{c}\text { 핵심전략 설정 } \\
\text { 미디어채널 터치포인트 설정 } \\
\text { 캠페인 로드맵 설정 } \\
\text { 소비자 여정 설정 }\end{array}$ & $\begin{array}{c}\text { 핵심전략이 도식적이고 단계적인가 } \\
\text { 미디어의 설계가 얼마나 효과적인가 } \\
\text { 캠페인 로드맵이 명확하게 그려졌는가 } \\
\text { 소비자가 공감할만한 소비자 여정인가 }\end{array}$ \\
\hline
\end{tabular}

\section{5. 결론 및 제언}

문화도시활동이 본격화되고 있은 상황에서 1 차 법정 문화도시로 선정된 7 개 도시의 브랜드전략과 활동을 분석하였다. 각 도시의 다양한 실행을 본 연구에서는 문화도시의 특성에 맞게 장소(Place), 행사(Promotion), 사람(People), 제품(Product)이라는 4가지 
관점에서 새롭게 분석하였다. 또한, 거시적인 관점에서 문화도시브랜딩을 타깃, 전략, 콘텐츠로 구분하여 평가하고 향후 세부적으로 측정할 수 있는 모형을 제시하였다. 본 연구의 결론은 다음과 같다.

첫째, 문화도시만의 브랜드 아이덴티티가 차별화되고 명확할수록 효과적이다. 문화도시마다 4P(Promotion, Product, Place, People)의 요소를 공통적으로 지니고 있지만, 한정된 커뮤니케이션 자원을 고려하면, $4 \mathrm{P}$ 중에서 차별적 요소에 집중되어야 함을 확인할 수 있었다. 이를 통해 제한된 도시자원을 효율적으로 개발할 수 있고 중장기적으로 최소의 비용과 노력으로 도시브랜드의 명확한 개성과 아이덴티티를 축적해나갈 수 있다.

둘째, 문화도시만의 일관된 경험을 제공하는 콘텐츠 개발 시나리오가 필요하다. 도시를 경험하는 지역 내외부 사람들에게 일관된 경험을 제공하기 위해서는 브랜드 아이덴티티 중심의 콘텐츠 개발 시나리오가 필요하다. 사용자가 소비하는 것은 지역의 콘텐츠이므로 콘텐츠를 경험하는 사용자 관점의 사용자 여정(User Journey)을 설계하는 것이 중요하다. 예를들어, 박인규 연구에서 밝힌 김천8경 역시 사용자 여정을 만들어낸 사례이다[17].

셋째, 핵심 타깃과 차별적 $4 \mathrm{P}$ 요소를 중심으로 선형적이거나 비선형적인 디지털스토리텔링이 지속가능해야한다. 핵심 타깃으로부터 가장 많은 콘텐츠가 생성되기 때문에 이들이 주로 사용하는 미디어채널이나 플랫폼에서 콘텐츠에 대한 스토리가 지속적으로 생성될 수 있도록 설계해야 한다. 특히, 댓글, 평가, 후기, 사진, 영상, 스토리 등 다양한 사용자 생성 콘텐츠가 사용자들 사이에서 자발적으로 공유 확산될 수 있도록 마케팅 스토리를 유도하는 것이 핵심이다. 즉, 콘텐츠의 방향이 도시의 브랜드 정체성을 향하고 있어야 한다. 본 연구는 문화도시 활동을 분석하는 새로운 $4 \mathrm{P}$ 를 도출하고 문화도시브랜딩 평가측정모형을 제시하였다. 그러나 본 연구는 $4 \mathrm{P}$ 의 도출과정에서 객관적인 검증이 부족했으며 평가측정모형의 항목 역시 객관적 방법론으로 세분화하지 못했다. 그리고 각 지역의 문화도시 전문가와 시민의 의견을 폭넓게 청취하지 못했다. 향후 연구에서는 이러한 점을 보완할 수 있기를 기대한다.

\section{References}

[1] Kim Yu Kyung, Strategic management of public brands, Korea: Hankyung Inc, (2013).

[2] Lee Jeong Hoon, Place branding model formation study, Korea: Gyeonggi development research center, (2006).

[3] Kim Yu Kyung, Strategic management of public brands, Korea: Hankyung Inc, (2013).

[4] G. Dooley, D. Bowie, Place brand architecture: Strategic management of the brand portfolio, Place Brand Public Dipl 1, (2005), pp.402-419. DOI: https://doi.org/10.1057/palgrave.pb.5990037

[5] T. Ikuta, K. Yukawa, H. Hamasaki, Regional branding measures in Japan - Efforts in 12 major prefectural and city governments, Place Branding and Public Diplomacy, (2007), Vol.3, No.2, pp.131-143.

[6] M. Kavaratzis, G. Ashworth, City branding: An effective assertion of identity or a transitory marketing trick?, Place Brand Public Dipl 2, (2006), pp.183-194. DOI: https://doi.org/10.1057/palgrave.pb.5990056

[7] Seungsik Yoon, Minchul Shin, Juyoung Kang, A Study on City Brand Evaluation Method Using Text Mining: Focused on News Media, Journal of Information Technology Services, (2019), Vol.18, No.1, p. 153-171.

[8] B. Parkerson, J. Saunders, City branding: Can goods and services branding models be used to brand cities?, Place Brand Public Dipl 1, (2005), pp.242-264. DOI: https://doi.org/10.1057/palgrave.pb.5990026

[9] Eunhee Choi, Jinho Lee, Research on intangible landmark through the analysis of Culture and Art industry of Busan, 
A Journal of Brand Design Association of Korea, (2013), Vol.11, No.2, p.95-104.

[10] Lee Seo Jin, Analysis on the City Brand Design Focusing on Its Periodic Characteristics and Trends, Journal of Korea Design Forum, (2019), Vol.24, No.3, pp.141-150, DOI: 10.21326/ksdt.2019.24.3.013

[11] Yan Bing, Yunyi Mo, The Relationship of Consumer Perceived Value, Online Word-of-Mouth and Behavioral Intention in Mobile E-commerce, International Journal of Smart Business and Technology, (2020), Vol.8, No.1, pp.13-20.

[12] ZihaoJin, Chae-Kwan Lim, A Study on the Influencing Factors of Customer Satisfaction and Continuous Use Intention in Mobile Payment Service, International Journal of Smart Business and Technology, (2020), Vol.8, No.2, pp.21-26.

[13] W.Y. Park, S. J. Lee, C. K. Park, S. H. Jung, H. K. Kim, The Effect of Service Quality of Internet Insurance on Intention to Purchase Online,International Journal of Smart Business and Technology, (2021), Vol.9, No.1, pp:63-70.

[14] Seung-Wan Ju, Lee-Sang Jung, The Effect of Exhibition Experience on the Intention of Purchase, International Journal of Smart Business and Technology, (2019), Vol.7, No.2, pp.39-44.

[15] Oh Ju-yeon, Research on Urban Brand Image and Influencers, Korea Advertising Promotional Journal, (2012), Vol.14, No.1, pp.182-217.

[16] Yang Seo, Koo Ja Jun, A Study on the Creative City Brand Identity System, Basic Geometry Research, (2019), Vol.20, No.2, pp.221-232.

[17] Park In Kyu, The Promotion of Tourism through Place Marketing of Local Tourism Resources, Korean Photographic Geographic Society, (2020), Vol.30, No.4, pp.83-97. 